\title{
Intratumoural renal cell carcinoma haemorrhage following stereotactic radiotherapy: a case report
}

\author{
Liam A. Hilleary ${ }^{1 *}\left(\mathbb{D}\right.$, Christopher Wratten $^{1,2}$, Shankar Siva ${ }^{3}$, Jenna Hilleary ${ }^{1}$ and Jarad M. Martin ${ }^{1,2}$
}

\begin{abstract}
Background: Stereotactic radiotherapy is an emerging treatment option for patients with inoperable renal cell carcinoma (RCC). Haemorrhage has not previously been reported to occur as a result of Stereotactic Body Radiotherapy (SBRT) to the kidney for primary RCC. We report an acute haemorrhage in a patient who received only one of three planned fractions of SBRT as part of a clinical trial.

Case presentation: A 74 year old female had a left renal mass under observation for 4 years, during which time she was imaged repeatedly using ultrasound and CT scans. There has been no evidence of metastases, and the lesion has demonstrated a steady pattern of growth over the 4-year period. Fine needle aspiration histologically confirmed RCC.

Following a multidisciplinary review, the patient was recommended for SBRT as she was not considered a surgical candidate. Treatment was planned for an ablative 42Gray (Gy) to be delivered in 3 fractions at 14Gy/fraction as part of a clinical trial. Our patient presented to the emergency department (ED) suffering left flank pain, fever and vomiting within $3 \mathrm{~h}$ of the first fraction of SBRT. CT showed the mass to have markedly increased in size, measuring $8.7 \times 8.1 \times 7.0 \mathrm{~cm}$, from $6.5 \times 5.4 \times 5.6 \mathrm{~cm}$. It was reported as an internal haemorrhage into the malignancy. The patient was admitted for analgesia, anti-pyretics, and transfusion of 2 units of packed red blood cells. The patient recovered without any further intervention but radiotherapy was discontinued. The patient was alive and free from disease progression two years after the aborted treatment.
\end{abstract}

Conclusion: Such events, though rare, are potentially serious, and therefore clinicians should be aware of such treatment related complications.

Keywords: Renal cell carcinoma, Stereotactic body radiotherapy, Spontaneous bleeding, Intratumoural bleeding

\section{Background}

Either partial or radical nephrectomy is the standard treatment for primary renal cell carcinoma (RCC) [1]. Thermal ablation approaches like radiofrequency ablation (RFA) or Cryotherapy are alternatives for small renal masses. Stereotactic Body Radiotherapy (SBRT) uses highly focused beam of X-Rays to cause genetic damage to cells, and has become a standard approach for treating a range of cancers including early primary lung tumours and brain metastases [2,3]. More recently, SBRT has been investigated as another approach of

\footnotetext{
* Correspondence: Liam.hilleary@calvarymater.org.au

${ }^{1}$ Calvary Mater Hospital, Locked Mail Bag 7 Hunter Region Mail Centre,

Newcastle, New South Wales 2310, Australia

Full list of author information is available at the end of the article
}

ablating inoperable abdominal tumours, including RCC, and has the advantage of being able to treat larger renal tumours $[4,5]$ due to its generous beam geometry when compared to the smaller ablation zone inflicted by microwave and radiofrequency ablation. Indeed, a pooled analysis of 223 patients managed with SBRT showed a 2 year rate of freedom from local progression of $100 \%$, justifying ongoing research in this area [4].

Due to their hypervascular nature, spontaneous haemorrhage has been reported in cases of RCC. Spontaneous haemorrhage can present as a symptom in the presentation of RCC, often characterised by flank pain and fever. In the treatment setting, bleeding is more commonly associated with invasive approaches such as radiofrequency ablation where a large study demonstrated

(c) The Author(s). 2019 Open Access This article is distributed under the terms of the Creative Commons Attribution 4.0 International License (http://creativecommons.org/licenses/by/4.0/), which permits unrestricted use, distribution, and 
haemorrhage in almost $6 \%$ of patients [6], or systemically administered targeted therapies like sorafenib, where it has been linked to fatal haemorrhage in the treatment of central lung tumours [7]. Here we present an unusual but serious adverse haemorrhage in a patient receiving SBRT to a primary RCC of the kidney.

\section{Case presentation}

A 74 year old female had a left renal mass under observation for 4 years, during which time she was imaged repeatedly using ultrasound and CT scans. Previous medical history includes obesity, diverticulosis, paroxysmal atrial fibrillation, diabetes mellitus, hypertension, and chronic kidney disease. Relevant medications included aspirin $100 \mathrm{mg} /$ day, which was not ceased. She ceased smoking 30 years ago. In December 2012, the lesion measured $39 \mathrm{~mm}$ in its largest dimension, and in July 2016 was measured at $65 \mathrm{~mm}$. There has been no evidence of metastases, and the lesion has demonstrated a steady pattern of growth over the 4-year period. Fine needle aspiration performed 3 months prior to presentation histologically confirmed the mass to be consistent with RCC.

Following a multidisciplinary review, the patient was recommended for SBRT as she was not considered a surgical candidate. The tumour was not amenable to thermal ablation due to size. She signed Informed Consent for a Human Research Ethics Committee approved clinical trial [5]. Treatment was planned for 42Gy to be delivered in 3 fractions at 14Gy per fraction as part of a prospective phase 2 collaborative clinical trial [5]. Noncontrast $3 \mathrm{D}$ and $4 \mathrm{D}$ CT scans were performed with 2 $\mathrm{mm}$ slice thickness. A recent contrast enhanced diagnostic CT was fused to the 3D planning CT.

A gross tumour volume (GTV) was contoured on the co-registered 3D CT scan, measuring $65 \mathrm{~mm}$ in its largest dimension. An internal target volume (ITV) was created by using 4D CT to account for breathing motion (Fig. 1). Motion observed was minimal, reaching $5 \mathrm{~mm}$ cranio-caudally, and $3 \mathrm{~mm}$ anterio-laterally. There was no posterior or medial motion observed. The planning target volume (PTV) was a $6 \mathrm{~mm}$ expansion of the ITV, optimised to remove regions overlapping with large bowel, with the ITV being used to define PTV extent in the region of overlap.

Varian Eclipse planning system was used for dose calculation and treatment was delivered using $10 \mathrm{MV}$ Flattening Filter Free (FFF) VMAT consisting of two coplanar, half rotation arcs, avoiding the right abdominal region.

A cone beam computed tomography scan (CBCT) was performed pre, mid, and post treatment, with corrections for intra-fractional motion being made prior to the delivery of each arc. Image matching was performed by two Radiation Therapists in consultation with the Radiation Oncologist. The GTV was easily defined on CBCT, as were proximal structures such as bowel and the renal artery and vein.

Within $3 \mathrm{~h}$ following the first fraction of SBRT, this patient presented to the emergency department suffering severe left flank pain, fever and vomiting. Contrast

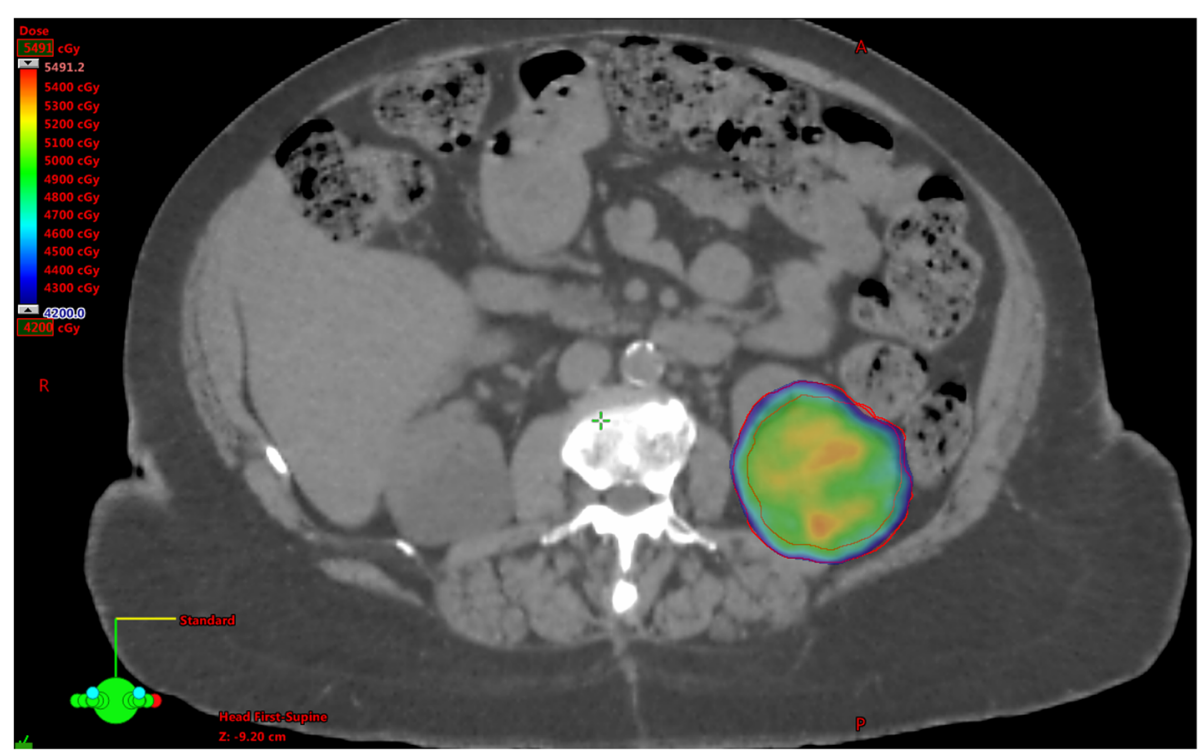

Fig. 1 legend: Axial view of dosimetry as seen on planning CT demonstrates doses ranging from 42Gy. Doses greater than 42Gy are restricted to the planning target volume (outer contour), and the dose was reduced in areas that overlap bowel. Note that due to the haemorrhage, treatment was suspended after 14Gy had been delivered 
enhanced CT showed the mass to have markedly increased in size, measuring $87 \times 81 \times 70 \mathrm{~mm}$, compared with $65 \times 54 \times 56 \mathrm{~mm}$ earlier the same day on CBCT which had been stable compared with her planning CT (Fig. 2). Intratumoral haemorrhage was noted with extension into the intraperitoneal space. The patient was admitted for analgesia, anti-pyretics, and transfusion of 2 units of packed red blood cells. The patient recovered without need for any further intervention but given this adverse reaction, radiotherapy was discontinued after $14 \mathrm{~Gy}$ as a single fraction. The patient remained in hospital for observation for a total of 8 days, and screening for coagulopathy was negative. Two years after the event the patient is stable, CT imaging showing a reduced mass measuring $55 \mathrm{~mm}$ in maximal diameter, similar to pre-treament imaging measurements on the day of radiotherapy, and suggesting on-going fibrosis and disease response. No metastatic lesions are evident, and dimercapto succinic acid (DSMA) split renal function scan shows $35 \%$ of function in the left kidney and an increasing estimated glomular filtration rate (eGFR) now to a level of 40.

\section{Discussion}

We report a patient with primary RCC who experienced an intratumoral haemorrhage immediately after receiving part of a planned ablative course of radiation therapy. Both in the preceding single centre study, and a larger multi-centre report of 223 patients, no similar events had been observed $[4,5]$. Research in animal cancer models has suggested that endothelial cells are relatively resistant to radiation induced apoptosis [6]. Never the less, haemorrhage has been reported as a possible

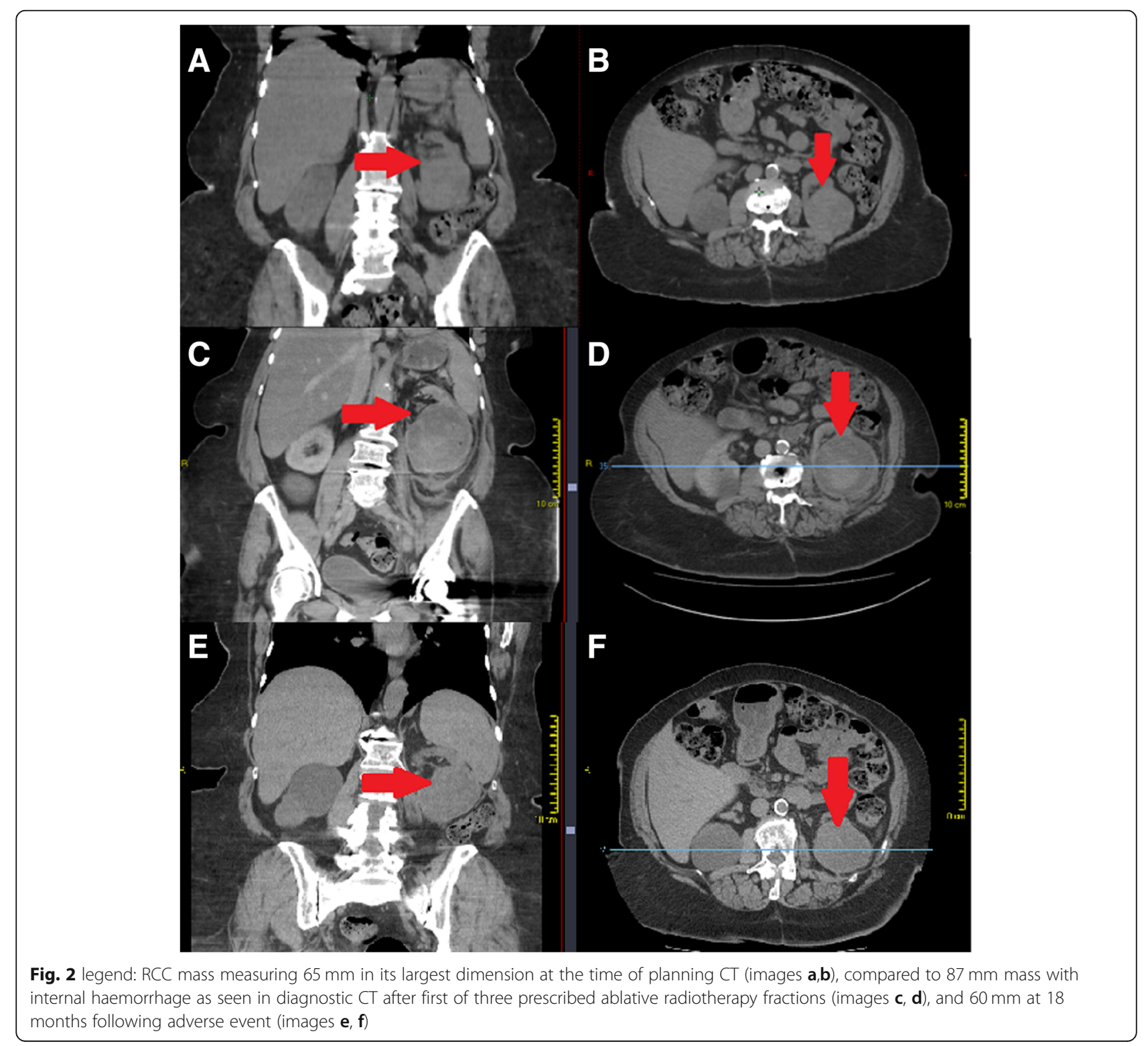


complication of cranial and pulmonary stereotactic radiotherapy (SRT) due to radionecrosis [7-9]. However, in the general oncology setting haemorrhage is often controlled, not caused, by radiotherapy. Hence radiotherapy is widely accepted as a standard treatment for many sites of haemorrhage associated with advanced cancer $[10,11]$.

Radionecrosis may be influenced by increased vasculature as well as increased radiosensitivity bought on by additional systemic therapies [7-11], especially when combined with hypofractionated radiotherapy. Our patient did not partake in such systemic therapies, however conditions such as diabetes, chronic renal insufficiency, and hypertension have been linked to reduced tolerance to radiotherapy [12, 13], and the pathways that lead to tumour shrinkage could disrupt the microvascular structure in a way that contributes to spontaneous or gradual bleeding. A magnetic resonance imaging study on the incidence of haemorrhage in patients with chronic renal insufficiency demonstrated that 12 of 13 consecutive patients exhibited intratumoral haemorrhage [14], an illustration of the fragile stroma of primary renal cell tumours. The precise mechanism of endothelial cell function in the face of radiation is very complex, including an array of cytokines, inherent endothelial cellular changes and interaction with circulating immune cells.

Thrombotic lesions can be produced following the release of cytokines when injury to the endothelial cells has occurred, and this has been used to explain bleeding events after cranial radiosurgery where haemorrhage is more frequently reported in the literature. Other hypotheses related to acute and late cranial bleeds include high feeding artery pressures and the increase in intravascular outflow resistance caused by venous obliteration, and more simply, there is the likelihood that large, vessel-rich tumours that were more likely to bleed if left untreated, will remain more likely to bleed even when treated [15-17]. Some possible causes stated in the literature are less relevant to body radiotherapy such as disruption to the blood brain barrier and the presence of pre-existing aneurisms proximal to the target region $[15$, 16]. Most commonly, post-treatment bleeding occurs as a delayed effect in the treatment of arteriovenous malformations (AVM), with a latency period of between 6 months and 3 years [16].In the intracranial metastasis setting, it should be noted that subacute intracranial bleeds following radiotherapy are mostly reported to have occurred over a longer time interval, with a study showing 10 intracranial tumour bleeds among $10 \mathrm{pa}-$ tients with metastatic lesions to have an interval period ranging from 1 day to 4 months [15].

We hypothesize that acute effects of the high dose of radiation on abnormal tumour endothelial cells in conjunction with mild anticoagulation in the form of aspirin was the mechanism behind the observed haemorrhage.

Although our patient was stabilised following haemorrhage, the required acute procedures such as blood transfusion carry additional risks such as infection and poorer response to medical treatments [18, 19]. Validated tools such as the HAS-BLED (Hypertension, Abnormal Renal/Liver Function, Stroke, Bleeding History or Predisposition, Labile INR, Elderly, Drugs/Alcohol Concomitantly) scoring criteria may be considered to assist with risk stratification [20-23]. Participant informed consent for the current study has been altered to reflect haemorrhage as a rare potential toxicity.

\section{Conclusion}

Given the timing relative to treatment delivery, we believe the acute haemorrhage to be a radiation-related effect. We hypothesize that endothelial disruption led to acute oedema and subsequent rupture of friable tumour neovasculature [24]. No similar events have been reported in the literature for primary extracranial lesions. Although unlikely, it is recommended that this risk is disclosed as part of informed consent, and that patients are aware of the experimental nature of SBRT for this indication.

\section{Abbreviations \\ 3D: Three dimensional; 4D: Four dimensional; AVM: Arteriovenous malformation; CBCT: Cone beam CT; CT: Computed tomography; \\ DSMA: Dimercapto succinic acid; eGFR: Estimated glomular filtration rate; FFF: Flattening filter free; GTV: Gross tumour volume; Gy: Gray; ITV: Internal target volume; MV: Megavolt; PTV: Planning target volume; RCC: Renal cell carcinoma; RFA: Radiofrequency ablation; SBRT: Stereotactic body radiotherapy}

\section{Acknowledgements}

We would like to acknowledge the assistance of Leisa Newton ${ }^{1}$ with draft reviews and review of final manuscript.

\section{Author's contributions}

$\mathrm{LH}$ conducted literature search, acquired and interpreted data and images, and drafted/authored manuscript. CW, SS, JH, JM contributed to literature search, histology reporting and were major contributors in writing manuscript. All authors read and approved the final manuscript.

\section{Funding}

If our manuscript is accepted into BMC Cancer, funding for costs relating to publication is to be provided by the:

Centre for Clinical Radiation Research at the University of Newcastle, University Drive, Callaghan New South Wales 2308.

Grant Number: 20171101.

This centre supplies funding in the form of an un-restricted grant and has played no role in the design of the study or collection, analysis, or interpretation of data, or in writing the manuscript.

Availability of data and materials

Not applicable.

Ethics approval and consent to participate

Written informed consent for participation was obtained from the patient. The associated clinical trial obtained ethics approval. A copy of the consent form is available for review by the Editor of this journal. 


\section{Consent for publication}

Written informed consent for publication of their clinical details and/or clinical images was obtained from the patient. A copy of the consent form is available for review by the Editor of this journal.

\section{Competing interests}

The authors declare that they have no competing interests.

\section{Author details}

'Calvary Mater Hospital, Locked Mail Bag 7 Hunter Region Mail Centre, Newcastle, New South Wales 2310, Australia. ${ }^{2}$ University of Newcastle School of Medicine and Public Health, University Drive, Callaghan, New South Wales 2308, Australia. ${ }^{3}$ Peter MacCallum Cancer Centre, Locked Bag 5m A'Beckett St, Melbourne, Victoria 8006, Australia.

Received: 22 September 2018 Accepted: 2 July 2019

Published online: 08 July 2019

\section{References}

1. Finelli A, Ismaila N, Bro B, et al. Management of Small Renal Masses: American Society of Clinical Oncology clinical practice guideline. J Clin Oncol. 2017:35:668-80.

2. Chang JY, Senan S, Paul MA, et al. Stereotactic ablative radiotherapy versus lobectomy for operable stage I non-small-cell lung cancer: a pooled analysis of two randomised trials. Lancet Oncol. 2015;16:630-7.

3. Won YK, Lee JY, Kang YN, et al. Stereotactic radiosurgery for brain metastasis in non-small cell lung cancer. Radiat Oncol J. 2015;33:207-16.

4. Siva S, Louie AV, Warner A, et al. Pooled analysis of stereotactic ablative radiotherapy for primary renal cell carcinoma: a report from the international radiosurgery oncology consortium for kidney (IROCK). Cancer. 2018;124:934-42

5. Siva S, Chesson B, Bressel M, et al. TROG 15.03 phase II clinical trial of focal ablative STereotactic radiosurgery for cancers of the kidney - FASTRACK II. BMC Cancer. 2018;18:1030.

6. Garcia-Barros M, Paris F, Cordon-Cardo C, et al. Tumor response to radiotherapy regulated by endothelial cell apoptosis. Science. 2003;300: 1155-9.

7. Agarwal A, Kanekar S, Thamburaj K, Vijay K. Radiation-induced spinal cord hemorrhage (hematomyelia). Neurol Int. 2014;6:5553.

8. Haseltine JM, Rimner A, Gelblum DY, et al. Fatal complications after stereotactic body radiation therapy for central lung tumors abutting the proximal bronchial tree. Pract Radiat Oncol. 2016;6:e27-33.

9. Kawasaki K, Hamamoto Y, Fukada J, et al. Fatal hemorrhage in a patient with advanced soft tissue sarcoma following radiation and pazopanib treatment: a case report. Oncol Lett. 2016;11:2408-10.

10. Tekatli H, Haasbeek N, Dahele M, et al. Outcomes of hypofractionated highdose radiotherapy in poor-risk patients with "ultracentral" non-small cell lung cancer. J Thorac Oncol. 2016:11:1081-9.

11. Fuks Z, Kolesnick R. Engaging the vascular component of the tumor response. Cancer Cell. 2005;8:89-91.

12. Dawson LA, Kavanagh BD, Paulino AC, et al. Radiation-associated kidney injury. Int J Radiat Oncol Biol Phys. 2010;76:S108-S15.

13. Chon BH, Loeffler JS. The effect of nonmalignant systemic disease on tolerance to radiation therapy. Oncologist. 2002;7:136-43.

14. John G, Semelka RC, Burdeny DA, et al. Renal cell cancer: incidence of hemorrhage on MR images in patients with chronic renal insufficiency. J Magn Reson Imaging. 1997;7:157-60.

15. Suzuki H, Toyoda S, Muramatsu M, Shimizu T, Kojima T, Taki W. Spontaneous haemorrhage into metastatic brain tumours after stereotactic radiosurgery using a linear accelerator. J Neurol Neurosurg Psychiatry. 2003; 74(7):908-12.

16. Pollock BE, Flickinger JC, Flickinger JC, Lunsford LD, Lunsford LD, Lunsford LD, Bissonette DJ, Kondziolka D, Kondziolka D. Hemorrhage risk after stereotactic radiosurgery of cerebral arteriovenous malformations. Neurosurgery. 1996;38(4):652-61.

17. Motozaki T, Ban S, Yamamoto T, Hamasaki M. Peritumoral hemorrhage after radiosurgery for metastatic brain tumor: a case report. No Shinkei Geka. 1994;22(8):789-93.

18. Malone DL, Dunne J, Tracy JK, Putnam AT, Scalea TM, Napolitano LM. Blood transfusion, independent of shock severity, is associated with worse outcome in trauma. J Trauma Acute Care Surg. 2003;54:898-907.
19. Eder AF, Chambers LA. Noninfectious complications of blood transfusion. Arch Pathol Lab Med. 2007;131:708-18.

20. Xing W, He X, Kassir MA, et al. Evaluating hemorrhage in renal cell carcinoma using susceptibility weighted imaging. PLoS One. 2013;8:e57691.

21. Pisters R, Lane DA, Nieuwlaat R, De Vos CB, Crijns HJ, Lip GY. A novel userfriendly score (HAS-BLED) to assess 1-year risk of major bleeding in patients with atrial fibrillation: the euro heart survey. Chest. 2010;138:1093-100.

22. Lip GY, Frison L, Halperin JL, Lane DA. Comparative validation of a novel risk score for predicting bleeding risk in anticoagulated patients with atrial fibrillation: the HAS-BLED (hypertension, abnormal renal/liver function, stroke, bleeding history or predisposition, labile INR, elderly, drugs/alcohol concomitantly) score. J Am Coll Cardiol. 2011;57:173-80.

23. Senoo K, Lane D, Lip GY. Stroke and bleeding risk in atrial fibrillation. Korean Circ J. 2014:44:281-90.

24. Scientific exhibits. J Med Imaging Radiat Oncol. 2017;61:138-97. https://doi. org/10.1111/1754-9485.12657.

\section{Publisher's Note}

Springer Nature remains neutral with regard to jurisdictional claims in published maps and institutional affiliations.

\section{Ready to submit your research? Choose BMC and benefit from:}

- fast, convenient online submission

- thorough peer review by experienced researchers in your field

- rapid publication on acceptance

- support for research data, including large and complex data types

- gold Open Access which fosters wider collaboration and increased citations

- maximum visibility for your research: over $100 \mathrm{M}$ website views per year

At BMC, research is always in progress.

Learn more biomedcentral.com/submissions 